\title{
A un siglo del \\ Manifiesto de Córdoba \\ (1918-2018)
}

\section{PRESENTACIÓN}

El próximo año se cumple el primer centenario de uno de los acontecimientos más importantes en la historia de la educación superior de América Latina, las acciones estudiantiles reivindicando un cambio en el sistema educativo. El Manifiesto de Córdoba de junio de 1918 recoge el sentir de los jóvenes estudiantes revolucionarios y de aquellos docentes que deseaban una casa de estudios inclusiva, integrada a la vida diaria de la sociedad; contribuyendo a la solución de los problemas de sus habitantes, compartiendo los avances de la ciencia.

Uno de los estudiosos de la educación superior de América Latina, Carlos Tünnermann Bernheim (2008), resume la importancia de Córdoba de 1918:

El movimiento de Córdoba que se inició en junio de 1918, fue la primera confrontación entre una sociedad que comenzaba a experimentar cambios de su composición social y una Universidad enquistada en esquemas obsoletos. La importancia de este movi- miento es tal que varios estudiosos de la problemática universitaria latinoamericana, sostienen que esta no puede ser entendida, en su verdadera naturaleza y complejidad, sin un análisis de lo que significa la Reforma de Córdoba, que dio un perfil propio a la Universidad de nuestra región... (La Reforma de Córdoba. Vientre fecundo de la transformación universitaria. Biblioteca CLACSO)

Por su parte la académica Sandra Carli (2009) destaca al autor del manifiesto, Deodoro Roca, quien a la sazón, era un joven influenciado por los cambios de la época. Este punto es esencial, porque Córdoba y sus implicaciones, deben de verse en ese contexto, de crisis del modelo capitalista y la emergencia de los movimientos revolucionarios. Carli señala en su escrito:

... El autor de este manifiesto fue Deodoro Roca (1890-1942), una figura valorada en su época, que fue homenajeado en distintas elegías por autores como Enrique González Tuñón y Rafael Alberti, especialmente res- 
catado en artículos, prólogos y estudios introductorios sobre su obra reunida. En 1918, Deodoro Roca era un joven de 28 años que pertenecía a los sectores tradicionales de Córdoba, doctorado en Derecho en la misma universidad, que tendría un papel activo, tanto en la emergencia como en el desarrollo del movimiento y del pensamiento reformistas. La combinación en sus escritos de elementos vinculados con el socialismo y la crítica antiimperialista, con el antipositivismo y el laicismo, con el juvenilismo y el humanismo cosmopolita, con el americanismo y el compromiso político, revelan la complejidad de un pensamiento que traduce un clima de época, así como el papel que ciertos intelectuales desempeñaron en los derroteros de los acontecimientos universitarios durante el siglo XX. Su pensamiento transitó del liberalismo al socialismo, del juvenilismo inicial - con componentes elitistas, románticos y antiintelectuales—a una posición latinoamericanista y antimperialista que lo acercaría a José Carlos Mariátigui y a Sandino. (Manifiesto liminar de la Reforma Universitaria. Federación Universitaria de Córdoba, 1918. Tomado de Trasatlántica de Educación Número 5, 2009. www.oei.es/noticias/spip.ph?article4571

A un siglo de Córdoba, los retos de la educación superior y de las universidades son mayores. Se vive una época de cambios, más que un cambio de época, donde las nuevas generaciones enfrentan desafíos desconocidos en aquella época. Ante esta realidad, se debe de trabajar, como ya se viene haciendo en alguna medida, en la Universidad del siglo XXI:

...transformar nuevamente la Universidad latinoamericana para que respondan a los desafíos de la sociedad contemporánea. Para ello, corresponde retar a la imaginación y replantearnos los objetivos, la misión y las funciones de las instituciones de educación superior, a fin de que estén a la altura de circunstancias actuales del nuevo milenio... (Tünnermann Bernheim, C. 2008, CLACSO) 